\title{
2038 - When Microbes Rule the Earth
}

Terry J. McGenity

Invited Editorial for Environmental Microbiology

\section{Introduction}

In celebration of the $20^{\text {th }}$ birthday of the journal Environmental Microbiology, I add a small, personal perspective on where I think the field of environmental microbiology / microbial ecology will go (or perhaps more accurately, should go) in the next 20 years. The title "2038 When Microbes Rule the Earth" is adapted from Bernard Dixon's inspirational book published more than 20 years ago (Dixon, 1994), and belies the fact that in many ways microbes already drive many Earth processes, including those in and on one of Earth's most influential multicellular organisms, Homo sapiens. However, 20 years from now it is reasonable for the optimistic microbiologist to expect that the bold microbial attribute of ruling the Earth will be more widely recognised and more extensively applied in the service of mankind, as detailed by Timmis et al. (2017) and other papers in the special issue of Microbial Biotechnology on the contribution of microbes to sustainable development goals. The acceleration of environmental change in the Anthropocene demands solutions, and environmental microbiology is at the core of shaping our future Earth (Webster et al., 2018). The following discussion attempts to illustrate why this is the case by considering topics that range from antibiotic resistance to the limits of life via global biogeochemical cycles, with common threads, such as microbial interactions and the need to cultivate the missing microbial majority.

\section{Dealing with antibiotic resistance}

Human-dwelling microbes are subject to the normal rules of ecology, and their activities can influence our physiology and psyche by: regulation of host gene expression, modulation of host epigenetic mechanisms, immune maturation and modulation, breakdown of hormones, release of signalling molecules, etc. (Sommer \& Bäckhed 2013; Schirmer et al., 2016; Fallows et al., 2018). This growing realisation of the importance of microbe-human interactions, coupled with developments in high-throughput sequencing, has led to a deluge of correlations between an organism's health and the composition of its microbiome. Now, by identifying causality and mechanisms there is the potential to greatly enhance the health of humans and a wide range of other organisms by microbiome engineering (Blaser et al., 2016).

However, some of those microbes with which we are in most intimate contact pose the greatest risk, as they are both primed to opportunistically infect us and under high selective pressure to develop multi-drug resistance. This is especially case for bacteria that colonise our gastrointestinal tract in large numbers, notably the Enterobacteriaceae (Hawkey et al., 2018). The spread of antibiotic resistance may allow microbes to rule the Earth in all the wrong ways - by leading to the proliferation of untreatable infectious disease and an ensuing global public health crisis

This article has been accepted for publication and undergone full peer review but has not been through the copyediting, typesetting, pagination and proofreading process, which may lead to differences between this version and the Version of Record. Please cite this article as doi: 10.1111/1462-2920.14449 
(www.who.int/drugresistance/en/). The solutions to this complex and serious problem are multifaceted, and, putting aside the important political, societal and clinical requirements (Hawkey et al., 2018), there is a pressing need to understand the ecology and biogeography of multi-drug resistant bacteria, and the key points at which their spread can be controlled (Berendonk et al., 2015). For example, the growing application of anaerobic digestion to transform animal waste into digestate for fertiliser (in addition to biogas for fuel), which is then spread onto agricultural land, has the potential to amplify and release antibiotic-resistance genes to the wider environment (Youngquist et al., 2016). Thus, the huge benefits of microbe-driven processes, like anaerobic digestion, which are vital for sustainable development, must be maintained while foreseeing and minimising any detrimental impacts.

Equally important is the need for improved mechanistic understanding of antibiotic resistance. Heterogeneity of gene expression and function within clonal microbial populations is a topic that will gain momentum in the $21^{\text {st }}$ century. The recent example of bacterial differentiation into metabolically distinct sub-populations to deal with stress-inducing overflow metabolites provides a tremendous step in understanding within-population division of labour (Rosenthal et al., 2018). Quiescent members of a bacterial population (known as persisters) are of direct relevance to antibiotic resistance by providing a subset of cells that are less susceptible to inhibition by virtue of their lack of growth. When they emerge from their quiescent state they are subjected to a low, residual concentration of antibiotics that provides the ideal selective environment for the build-up of resistance (Lewis, 2013). Thus, a strategy to target persisters, e.g. via prodrugs that are activated by intracellular enzymes from the target microbes, is essential for effective treatment of infections (Lewis, 2013). Microbial efflux pumps, which serve multiple roles, e.g. in virulence and community behaviour, are known primarily for eliminating chemical stressors and toxins from the cell, which provides a front-line mechanism of antibiotic resistance, and buys time for more specific antibiotic resistance mechanisms to evolve (Du et al., 2018). High-resolution insights into their assembly and operation in both the resting and transport-engaged states have identified novel drug targets, such as the interaction interfaces between the components of the RND-based tripartite efflux pump AcrAB-TolC, which spans the inner and outer membrane of Gram-negative bacteria (Wang et al., 2017). Indeed, the Periplasmic Adaptor Proteins, which create a versatile conduit between inner and outer-membrane compartments (Symmons et al., 2015), have proven to be potentially important targets for known drugs, allowing the revived application of defunct antibiotics (Abdali et al., 2017). A concerted effort is needed to more fully understand the complex interplay of the gamut of antibiotic-resistance mechanisms, including and beyond multi-drug efflux pumps, and to develop adjuvants for use alongside antibiotics to extend their functionality and longevity (Gonzalez-Bello, 2017).

The century-old practice of phage therapy is gaining traction globally as a means of controlling bacterial infections. There can be little doubt that in 20 years the application of phage will form a larger part of the therapeutic arsenal in some form, such as: native or genetically modified phage, as phage cocktails, combined with antibiotics or with enzymes that degrade the polymeric component of biofilms, or phage-derived lytic proteins (Lin et al., 2017; Pires et al., 2017). But phage therapy is not a panacea and there remains an urgent need for antibiotics with new modes of action. Microbes produce an array of bioactive compounds, which have served as molecular frameworks for new therapeutics, including new antibiotics, for many years (Lewis, 2013; Tracanna et al., 2017). However, in addition to a reluctance to invest in developing drugs for acute illnesses, pharmaceutical 
companies saw diminishing returns of new structures from their screening programmes in recent decades. Perhaps the resultant unwillingness to screen for microbial natural products is changing (Harvey et al., 2015) because of a growing recognition that targeting different taxonomic groups, and including genome-centred searches, can expand the diversity of lead molecules detected (Pye et al., 2017; Tracanna et al., 2017). The taxonomic space occupied by cultivated microbes eclipses that of all other types of organism, and if we add the many yet-to-be cultivated bacterial and archaeal phyla (see Koonin, 2018) the taxonomic, and thus chemical, diversity expands markedly (Li and Qin, 2015). Smarter and higher-throughput cultivation techniques will become increasingly important in microbiology in general (see later) and specifically can yield novel antibiotics (Ling et al., 2015). Similarly, our grasp of the microbial metabolome, and especially the roles of metabolites in signalling, falls woefully behind our understanding of the genome, transcriptome and proteome, and developments in metabolite analysis and data sharing should help in the search for new antibiotics (Wang et al., 2016). Even without mechanistic understanding, the knowledge that microbes produce different metabolites when grown in co-culture, under stress or as biofilms, compared with traditional pure culture in optimised liquid medium, can be used to broaden the hunt for antibiotics (Molinari, 1999; Shi et al., 2017). Metagenomic techniques allow access to novel genetic material from uncultivated microbes, which can be expressed in a host organism and screened for antibiotic activity (Crits-Christoph et al., 2018). However, more targeted metagenomic searches for known bioactive metabolites (e.g. produced from sessile marine animals), in conjunction with cell sorting and whole-genome amplification, are perhaps proving a more fruitful means to identify the microbial source of bioactive compounds and their biosynthetic gene clusters, which then allows scale-up and development to market (Trindade et al., 2015). Overall, in order to meet the challenge of antibiotic resistance in the next 20 years, global stewardship must be informed by a vastly improved understanding of cultivated and yet-to-be-cultivated microbes, from their biochemistry to their ecology (Allen et al., 2010).

\section{Capturing microbial novelty}

A number of interconnected concepts arose in the foregoing discussion that merit elaboration in the broader context of environmental microbiology: cultivation, co-cultivation, synthetic communities, and microbial interactions with each other and their biotic and abiotic environment. Pure cultures are by far the most convenient way to investigate microbes, but many microbes cannot grow, or cannot do so easily or rapidly, in pure culture. The application of the candidate genus and species concept has assisted in communicating the value of highly enriched, but not pure, cultures of microbes (Konstantinidis and Rosselló-Móra, 2015). Microbiologists will need to develop platforms to describe, archive and disseminate mixed cultures, which by their very nature may differ when investigated at different times and in different laboratories. However, given the importance of mixed microbial cultures, from polymicrobial infections to biogeochemical cycles, and the relative ease by which their component microbes can be identified and quantified, it is essential and feasible, respectively, to produce a systematic means of cross-laboratory investigation. In 20 years it is hoped that the vital role of microbiological culture collections will be more widely recognised and their funding increased, such that, in addition to being custodians of pure cultures, they can hold thousands of candidate species as well as enrichment cultures, especially those including microbes from novel taxa and carrying out processes that require multiple species. 
Single-cell genomics and genomic reconstruction from metagenomes will continue to provide valuable insights into the potential metabolism of enigmatic microbes (Bowers et al., 2017). The latter is exemplified by considering the extremely important trait of methane production. It was, until recently, assumed that the extensively investigated process of methanogenesis was restricted to certain phylogenetic lineages of Euryarchaeota. Now, methyl-reducing methanogenesis has been implicated in non-euryarchaeal candidate phyla within the Archaea, such as the "Verstraetearchaeota" (Vanwonterghem et al., 2016) and "Bathyarchaeota" (Evans et al., 2015). Moreover, some members of the "Bathyarchaeota", a very abundant and diverse group found in marine sediments and formerly referred to as Miscellaneous Crenarchaeotal Group, have been implicated in acetogenesis, a trait previously found only in Bacteria (He et al., 2016). Thus, within just one phylum, which has no cultivated representatives, there is evidence of a plethora of classes and orders carrying out diverse functions (Zhou et al., 2018).

Understanding the relationship between community structure and ecosystem processes is a fundamental goal of ecology (Green et al. 2008). The relative ease of microbial community analysis by metagenetic, metagenomic and metatranscriptomic approaches makes the development of tools that can inform on the microbial health of a system (from the deep sea to anaerobic digestors) an attractive proposition. However, the application of this information, for example to understand how differences or changes in community structure affect ecosystem processes, requires extrapolation from taxonomy to trait (or for metagenomics, inference of true function from functional-gene sequence). Martiny et al. (2013) provided a theoretical framework to explain different levels of taxonomy-trait relationship in Bacteria and Archaea, and a plethora of bioinformatics tools are being developed to make this extrapolation (Langille et al. 2013). In addition, the potential value of microbial sequences as "biosensors" of environmental pollutants has been demonstrated by Smith et al. (2015). However, the foregoing snapshot from the "Bathyarchaeota", one of dozens of diverse, yet-to-be cultivated phyla, highlights the need to better understand the functions of microbial dark matter if we want to relate sequence to function and more accurately predict how processes will be affected by environmental change. For example, questions about metabolic processes and their controlling elements in phyla such as the "Bathyarchaeota" could be much more readily and convincingly addressed if they were brought into culture. Thus, there is the need for more innovative cultivation techniques to capture novel, hitherto uncultivated microbes, either in pure culture or co-culture, and start to bridge the divide between increasingly easily-won sequence data and hard-earned cultivation and in-depth physiological, functional genomic and biochemical characterisation (Ling et al., 2015; McGenity 2016; Overmann et al., 2017). Pure cultures allow reproducible investigation, but microbes almost never exist as single species in nature, leading to artefactual Petri-dish activities and the potential to lose and gain traits after laboratory sub-culturing (Tenaillon et al., 2016). Therefore, a complementary mix of analyses from the field to the gene is needed to gain a holistic understanding of microbial activities and interactions in their native environments, applying methods such as stable-isotope probing, especially coupled with Raman microspectroscopy, which can link phylogeny to function (Singer et al., 2017). A seemingly futuristic world in which we know in-depth and in hours which microbes are present in a sample is upon us, but in 20 years microbial ecologists will still be employed to understand what those microbes are doing and with whom, requiring collaborative efforts between experimentalists and the modelling community to predict the function and dynamics of microbial communities (Widder et al., 2016). 
As mentioned above, we are still learning about microbial processes like methanogenesis, but there are many other biogeochemical processes that are predicted to be driven by microbes, about which we need to learn a lot more. This search was articulated as "the hunt for the most-wanted chemolithoautotrophic spookmicrobes" (in 't Zandt et al., 2018). The hunt for spookmicrobes generally starts with biogeochemical evidence, such as co-localised depletion, which could not be explained by physical processes, of two compounds that could react to generate energy, and may include stable- and radio-isotopic evidence of microbial involvement. A classic example is the discovery of anaerobic methane oxidation (see in 't Zandt et al., 2018), for which we now know the microbes that couple the oxidation of methane to terminal electron acceptors such as sulfate, nitrate and nitrite, while the Archaea that use Fe(III) as terminal electron acceptor evaded identification until very recently (Cai et al., 2018). Genomic reconstruction of "Candidatus Methylomirabilis oxyfera", the dominant member of a culture carrying out nitrite-dependent anaerobic oxidation of methane, has revealed a fascinating mechanism whereby it converts nitrite to nitric oxide, which is dismutated to nitrogen and oxygen, and the latter is then used to oxidise methane by the well-known aerobic pathway (Ettwig et al. 2010).

The microbial cycling of methane has been the subject of more than a thousand scientific publications, partly because it is a potent greenhouse gas; yet the last decade has seen the discovery of new mechanisms for its production and consumption, and identification of new phyla involved in methane cycling, as outlined above. However, methane is far from the only volatile compound produced and/or consumed by microbes that influences the climate. Terpenes and oxygenated volatile organic compounds are just two classes of volatiles that have been largely neglected by microbiologists. Isoprene, for example, which is liberated to the atmosphere (primarily by plants, but also by phototrophic and heterotrophic microbes) to a similar extent as methane, serves as a carbon and energy source for bacteria, and can be consumed at environmentally relevant concentrations (McGenity et al., 2018). We are beginning to understand the ecology, cryptic cycles, functional genomics and physiology of the microbes involved in transforming this very abundant volatile compound, as well as its role as a signalling molecule (see Fall and Copley, 2000; McGenity et al., 2018). One important detrimental effect of isoprene is its reaction with nitrogen oxides (NOx) to create ground-level ozone, with ensuing damage to crop and animal health (Ashworth et al., 2013), which is likely to be exacerbated by increased planting of isoprene-producing crops such as poplar, willow and oil palm, especially near urban areas where NOx concentrations are high (Ashworth et al., 2013). This brief discussion of a single volatile organic compound serves to illustrate a number of important points: 1) land management practices must consider the fact that carbon-neutral does not necessarily equate to climate-neutral; 2 ) there are complex interactions between biogeochemical cycles (e.g. some aforementioned NOx may be microbially derived); 3 ) microbial activities (e.g. in this case isoprene-degrading microbes) may be harnessed to mitigate damaging effects.

Isoprene is, however, one of a multitude of biogenic volatile organic compounds, which in turn represent just one class of metabolites, many of which produce an array of biopolymers. The complexity of just one, albeit very important, process, namely permafrost warming, was illustrated by Kramshøj et al. (2018), who identified 316 organic ions (representing distinct volatile compounds) released upon thawing. However, the vast majority of the most abundant compounds, ethanol and methanol, were consumed by microbes, restricting their escape to the atmosphere (Kramshøj et al., 2018). Microbial chemolithoautotrophic growth on gases, such as $\mathrm{H}_{2}, \mathrm{CO}$ and $\mathrm{CO}_{2}$ captured from the atmosphere, appears to be a quantitatively important complement to photosynthetic primary 
production in Antarctic desert soils, even exceeding it in particular locations and certainly during austral winters (Ji et al., 2017). Thus, a major challenge for the next 20 years will be to more fully understand (using gene-to-ecosystem approaches) the role of microbes in driving global biogeochemical cycles in the context of environmental change, while judiciously selecting for detailed investigation those compounds that are likely to have most impact on the atmosphere and environment.

\section{Microbes working together}

One of the earliest papers in Environmental Microbiology elegantly demonstrated the value of the "community metabolic pathway" in degrading pollutants (Pelz et al., 1999). It is now widely recognised that in nature metabolic steps are compartmentalised in different microbial species, and the resultant consortia are generally considered to be more resilient and efficient at using resources (De Roy et al., 2014). Indeed, a large fraction of a microbe's genome (17-42\%) is dedicated to facilitating interactions (Phelan et al., 2012). More generally, the field of synthetic community ecology, the rational design and control of microbial communities, is gaining momentum in biotechnology and in addressing fundamental ecological questions (De Roy et al., 2014). Broader application of rationally designed communities will develop over the next 20 years with a more mechanistic understanding of cross-feeding and syntrophic interactions and the production of public goods (such as extracellular polymeric substances or extracellular enzymes), as well as with improved analysis of metabolites (Cavaliere et al., 2017). Understanding and minimising the switch from cooperative to competitive behaviour, and in particular how to limit "cheating" by members of a consortium, will make the functioning of consortia more reliable (Lindemann et al., 2016; Cavaliere et al., 2017). Several approaches are being used to make consortia more productive, manageable and predictable for bioengineers, for example by optimising spatial organisation of species so that they can grow under ideal conditions while allowing metabolite exchange with their partner species, all of which is aided by developments in microfluidics, microfabrication and microsensors (Ben Said and Or, 2018; Seymour et al., 2017).

Particularly exciting is the new insight into how phytoplankton, which are responsible for around half the global primary production (Field et al., 1998), rely on interactions with heterotrophs. Thus, phototroph-heterotroph interactions, involving exchange of metabolites and modulation of growth, are vital for global biogeochemical cycles, especially oxygen production and $\mathrm{CO}_{2}$ fixation (Seymour et al., 2017). Indeed, the circulation of nutrients is probably essential for their stable co-existence (Christie-Oleza et al., 2017). Phytoplankton may also play a hitherto poorly recognised role in the remediation of crude oil. Cyanobacteria, for example, produce hydrocarbons that could sustain populations of hydrocarbonoclastic bacteria and contribute to a potentially large-scale cryptic hydrocarbon cycle in the oceans (Lea-Smith et al., 2015), and microalgal phototrophs in general enhance hydrocarbon biodegradation by supplying oxygen and other compounds to associated bacteria (McGenity et al., 2012). The next 20 years will see an accelerated move towards biotechnological processes using mixed cultures of diverse constellations, both bottom-up designed and top-down tamed, underpinned by an improved understanding of how microbial molecular cocktails influence social behaviour and by predictive models to provide efficient and stable processes (Richter et al., 2018; Cavaliere et al., 2017; Widder et al., 2016; Hays et al., 2015). 


\section{Microbes in extremis}

Microbial life pervades our planet, even in extremely hostile environments; yet we still do not know how microbes evolved to survive or grow in environments with little energy and a multitude of stressors. Microbial activity in the deep subsurface can transform the geosphere, for example by coupling the oxidation of hydrocarbons with sulfate derived from gypsum $\left(\mathrm{CaSO}_{4} \cdot 2 \mathrm{H}_{2} \mathrm{O}\right)$ as terminal electron acceptor, liberating $\mathrm{CO}_{2}$ and resulting in the replacement of gypsum with calcium carbonate (Ziegenbalg et al., 2012). Most microbes, however, may be simply surviving in deep sediments. Out of all the environmental parameters that can limit life, energy is perhaps the least understood and most important. There is evidence of microbial survival over millions of years based on cultivation (Gramain et al., 2011) and geochemical profiling (Røy et al., 2012). Moreover, by modelling the energetic requirements for essential biomolecular repair, such long-term survival seems feasible with known supplies of organic matter, including necromass, and hydrogen generated by radiolysis of water (Lever et al., 2015; Bradley et al., 2018). However, we do not fully understand the conditions that can sustain life, or the boundaries between living and dead. Laboratory-determined values of maintenance energy, for example, probably greatly over-estimate natural requirements (LaRowe and Amend, 2015). Therefore, we need to learn much more about the available pools of electron donors and acceptors (Lever et al., 2015), the capabilities of microbial consortia to optimally access them, and the capacities of microbes, or their habitats, to limit damage to biomolecules thus lessening the required maintenance energy.

Extreme environments can be considered as "islands" for adapted extremophiles, which can thus serve to address fundamental questions about microbial biogeography (Clark et al., 2017). However, most so-called extreme environments are not mere peculiarities, for example the cold deep sea and the hot deep subsurface are among the most voluminous habitats on Earth, while desiccated and hypersaline environments cover vast areas of subtropical continents. Thus, biogeochemical processes within such environments influence greatly the Earth and its atmosphere. Developing our understanding of the limits of life will also help to determine whether we are alone in the universe, as in the coming decades we search for life on Mars, the icy moons Europa and Enceladus, and beyond. For all of the foregoing reasons it is important to determine the windows of life, the boundaries of which are continuously being stretched. For example, the water activity limit for growth of 0.605 (Stevenson et al., 2015) has been reduced to 0.585 in the fungus Aspergillus penicillioides (Stevenson et al., 2016). While, Planococcus halocryophilus, isolated from high Arctic permafrost, divides at $-15^{\circ} \mathrm{C}$ and remains metabolically active at $-25^{\circ} \mathrm{C}$ (Mykytczuk et al., 2013).

In order to predict where life may be found it will be important to deconstruct certain stressors, in particular salinity, which is a bulk term that disguises variations in ionic composition of brines. This was highlighted by investigating the deep-sea hypersaline anoxic brine lakes of the Mediterranean, one of which, named Discovery, was an almost pure, saturated $\mathrm{MgCl}_{2}$ brine (Hallsworth et al., 2007). At the interface between seawater and the saturated brine, microbial activity (determined by mRNA detection from sulfate reducers and methanogens) was not found at or above $2.64 \mathrm{M} \mathrm{MgCl}_{2}$, which corresponds with a water activity of 0.770 (Hallsworth et al., 2007), well within the limits for halophilic growth (Stevenson et al., 2015). The macromolecule-destabilising (chaotropic) properties of $\mathrm{MgCl}_{2}$ were considered to be the life-limiting factor (Hallsworth et al., 2007). However, in another 
deep-sea lake, named Kryos, sulfate reduction activity was found at much higher $\mathrm{MgCl}_{2}$ concentrations corresponding to a water activity of 0.4 and chaotropicity far beyond the currently known limits of life (Steinle et al., 2018). This finding should inspire a search for organisms seemingly active way beyond known limits. Furthermore, ionic composition (balance of kosmotropes and chaotropes) as well as the overall ionic strength of brines, together with microbial adaptations to counter these effects, will be key factors in determining brine habitability (Hallsworth et al., 2007; Lima de Alves et al., 2015; Fox-Powell et al., 2016). In addition, the synergistic and antagonistic effects on microbes of multiple environmental stressors, despite being the norm, require much more in-depth investigation in order to predict biological processes on Earth and elsewhere (Harrison et al., 2013).

\section{Final word}

The marvel of environmental microbiology is that its notions are frequently turned on their head, as exemplified by the discovery of cyanobacteria, generally known for their photosynthetic activity, as the dominant members of a deep, dark sub-surface environment that forms part of the lberian Pyrite Belt (Puente-Sánchez et al., 2018). Metagenomic and geochemical evidence point toward the possibility of hydrogen-based chemolithoautotrophic metabolism by these cyanobacteria that are phylogenetically related to endolithic species (Puente-Sánchez et al., 2018). Thus, we have a situation in which some cyanobacteria do not generate oxygen (Puente-Sánchez et al., 2018) while methanotrophic "Candidatus Methylomirabilis oxyfera" does generate oxygen (Ettwig et al. 2010), opening up questions about the evolution of oxygen on Earth, as well as confirming the view that the field of environmental microbiology will be throwing up surprises, that influence diverse disciplines and that have important societal consequences, up to and beyond 2038.

\section{References}

Abdali, N., Parks, J.M., Haynes, K.M., Chaney, J.L., Green, A.T., Wolloscheck, D. et al. (2017) Reviving antibiotics: efflux pump inhibitors that interact with AcrA, a membrane fusion protein of the AcrABTolC multidrug efflux pump. ACS Infect Dis 3: 89-98.

Allen, H.K., Donato, J., Wang, H.H., Cloud-Hansen, K.A., Davies, J., and Handelsman, J. (2010) Call of the wild: antibiotic resistance genes in natural environments. Nat Rev Microbiol 8: 251-259.

Ashworth, K., Wild, O., and Hewitt, C.N. (2013) Impacts of biofuel cultivation on mortality and crop yields. Nat Clim Change 3: 492-496.

Ben Said, S., and Or, D. (2017) Synthetic microbial ecology: Engineering habitats for modular consortia. Front Microbiol 8: 1125.

Berendonk, T.U., Manaia, C.M., Merlin, C., Fatta-Kassinos, D., Cytryn, E., Walsh, F., et al. (2015) Tackling antibiotic resistance: the environmental framework. Nat Rev Microbiol 13: 310-317. 
Blaser, M.J., Cardon, Z.G., Cho, M.K., Dangl, J.L., Donohue, T.J., Green, J.L. et al. (2016). Toward a predictive understanding of Earth's microbiomes to address $21^{\text {st }}$ century challenges. mBio 7: e0071416.

Bowers, R.M., Kyrpides, N.C., Stepanauskas, R., Harmon-Smith, M., Doud, D., Reddy, T.B.K et al. (2017) Minimum information about a single amplified genome (MISAG) and a metagenomeassembled genome (MIMAG) of bacteria and archaea. Nat Biotechnol 35: 725-731.

Bradley, J.A., Amend, J.P., and LaRowe, D.E. (2018) Survival of the fewest: Microbial dormancy and maintenance in marine sediments through deep time. Geobiol doi:10.1111/gbi.12313.

Cai C., Leu A.O., Xie G.-J., Guo J., Feng Y., Zhao J.-X., et al. (2018) A methanotrophic archaeon couples anaerobic oxidation of methane to Fe(III) reduction. ISME J 12: 1929-1939.

Cavaliere, M., Feng, S., Soyer, O.S., and Jimenez, J.I. (2017) Cooperation in microbial communities and their biotechnological applications. Environ Microbiol 19: 2949- 2963.

Christie-Oleza, J.A., Sousoni, D., Lloyd, M., Armengaud, J., and Scanlan, D.J. (2017) Nutrient recycling facilitates long-term stability of marine microbial phototroph-heterotroph interactions. Nat Microbiol 2: 17100 .

Clark, D.R., Mathieu, M., Mourot, L., Dufossé, L., Underwood, G.J.C., Dumbrell, A.J., and McGenity, T.J. (2017) Biogeography at the limits of life: Do extremophilic microbial communities show biogeographic regionalisation? Glob Ecol Biogeog 26: 1435-1446.

Crits-Christoph, A., Diamond, S., Butterfield, C.N., Thomas, B.C., and Banfield, J.F. (2018) Novel soil bacteria possess diverse genes for secondary metabolite biosynthesis. Nature 558: 440-444.

De Roy, K., Marzorati, M., Van den Abbeele, P., Van de Wiele, T., and Boon, N. (2014) Synthetic microbial ecosystems: an exciting tool to understand and apply microbial communities. Environ Microbiol 16: 1472-1481.

Dixon, B. (1994) Power unseen: how microbes rule the world. New York: Freeman.

Du, D., Wang-Kan, X., Neuberger, A., van Veen, H.W., Pos, K.M., Piddock, L.J.V., and Luisi, B.F. (2018) Multidrug efflux pumps: structure, function and regulation. Nat Rev Microbiol 16: 523-539.

Ettwig, K.F., Butler, M.K., Le Paslier, D., Pelletier, E., Mangenot, S. et al. (2010) Nitrite-driven anaerobic methane oxidation by oxygenic bacteria. Nature 464: 543-548.

Evans, P.N., Parks, D.H., Chadwick, G.L., Robbins, S.J., Orphan, V.J., Golding, S.D., and Tyson, G.W. (2015) Methane metabolism in the archaeal phylum Bathyarchaeota revealed by genome-centric metagenomics. Science 350: 434-438.

Fall, R., and Copley, S.D. (2000) Bacterial sources and sinks of isoprene, a reactive atmospheric hydrocarbon. Environ Microbiol 2: 123-130.

Fellows, R., Denizot, J., Stellato, C., Cuomo, A., Jain, P., Stoyanova, E. et al. (2018) Microbiota derived short chain fatty acids promote histone crotonylation in the colon through histone deacetylases. Nat Comm 9: 105. 
Field, C.B., Behrenfeld, M.J., Randerson, J.T., and Falkowski, P. (1998) Primary production of the biosphere: integrating terrestrial and oceanic components. Science 281: 237-240.

Fox-Powell, M.G., Hallsworth, J.E., Cousins, C.R., and Cockell, C.S. (2016) lonic strength is a barrier to the habitability of Mars. Astrobiology 16: 427-442.

Harvey, A.L., Edrada-Ebel, R., and Quinn, R.J. (2015) The re-emergence of natural products for drug discovery in the genomics era. Nat Rev Drug Discovery 14: 111-129.

Hays, S.G., Patrick, W.G., Ziesack, M., Oxman, N., and Silver, P.A. (2015) Better together: engineering and application of microbial symbioses. Curr Opin Biotechnol 36: 40-49.

Gonzalez-Bello, C. (2017) Antibiotic adjuvants - a strategy to unlock bacterial resistance to antibiotics. Bioorg Med Chem Lett 27: 4221-4228.

Gramain, A., Chong Díaz, G., Demergasso, C., Lowenstein, T.K., and McGenity, T.J. (2011) Archaeal diversity along a subterranean salt core from the Salar Grande (Chile). Environ Microbiol 13: 21052121.

Hallsworth, J.E., Yakimov, M.M., Golyshin, P.N., Gillion, J.L.M., D’Auria, G., de Lima Alves, F. et al. (2007) Limits of life in $\mathrm{MgCl}_{2}$-containing environments: Chaotropicity defines the window. Environ Microbiol 9: 801-813.

Harrison, J.P., Gheeraert, N., Tsigelnitskiy, D., and Cockell, C.S. (2013) The limits for life under multiple extremes. Trends Microbiol 21: 204-212.

He, Y., Li, M., Perumal, V., Feng, X., Fang, J., Xie, J., Sievert, S.M., and Wang, F. (2016) Genomic and enzymatic evidence for acetogenesis among multiple lineages of the archaeal phylum Bathyarchaeota widespread in marine sediments. Nat Microbiol 1: 16035.

in 't Zandt M.H., de Jong A.E.E., Slomp C.P., and Jetten M.S.M. (2018) The hunt for the most-wanted chemolithoautotrophic spookmicrobes. FEMS Microbiol Ecol 94: fiy064.

Ji, M., Greening, C., Vanwonterghem, I., Carere, C.R., Bay, S.K., Steen, J.A. et al. (2017) Atmospheric trace gases support primary production in Antarctic desert surface soil. Nature 552: 400-403.

Konstantinidis, K., and Rosselló-Móra, R. (2015) Classifying the uncultivated microbial majority: a place for metagenomic data in the Candidatus approach. Syst Appl Microbiol 38: 223-230.

Koonin, E.V. (2018) Environmental microbiology and metagenomics: the Brave New World is here, what's next? Environ Microbiol doi: 10.1111/1462-2920.14403.

Kramshøj, M., Albers, C.N., Holst, T., Holzinger, R., Elberling, B., and Rinnan, R. (2018) Biogenic volatile release from permafrost thaw is determined by the soil microbial sink. Nat Comm 9: 3412 .

Langille, M.G., Zaneveld, J., Caporaso, J.G., McDonald, D., Knights, D., Reyes, J.A. et al. (2013) Predictive functional profiling of microbial communities using $16 \mathrm{~S}$ rRNA marker gene sequences. Nat Biotechnol 8: 1-10.

LaRowe, D.E., and Amend, J.P. (2015) Power limits for microbial life. Front Microbiol 6: 1-11. 
Lea-Smith, D.J., Biller, S.J., Davey, M.P., Cotton, C.A., Perez Sepulveda, B.M., Turchyn, A.V., et al., (2015) Contribution of cyanobacterial alkane 762 production to the ocean hydrocarbon cycle. Proc Natl Acad Sci USA 112: 13591-13596.

Lever, M.A., Rogers, K.L., Lloyd, K.G., Overmann, J., Schink, B., Thauer, R.K., Hoehler, T.M. , and Jørgensen, B.B. (2015) Life under extreme energy limitation: a synthesis of laboratory- and fieldbased investigations. FEMS Microbiol Rev 39: 688-728.

Lewis, K. (2013) Platforms for antibiotic discovery. Nature Rev Drug Discov 12: 371-387.

Li, X., and Qin, L. (2005) Metagenomic-based drug discovery and marine microbial diversity. Trends Biotechnol 23: 539-543.

Lima de Alves, F., Stevenson, A., Baxter, E., Gillion, J.L.M., Hejazi, F., Hayes, S. et al. (2015) Concomitant osmotic and chaotropicity-induced stresses in Aspergillus wentii: compatible solutes determine the biotic window. Curr Genetics 61: 457-477.

Lin, D.M., Koskella, B., and Lin, H.C. (2017) Phage therapy: an alternative to antibiotics in the age of multi-drug resistance. World J Gastrointest Pharmacol Ther 8: 162-173.

Lindemann, S.R., Bernstein, H.C., Song, H.-S., Fredrickson, J.K., Fields, M.W., Shou, W., et al. (2016) Engineering microbial consortia for controllable outputs. ISME J 10: 2077-2084.

Ling, L.L., Schneider, T., Peoples, A. J., Spoering, A.L., Engels, I., Conlon, B.P. et al. (2015) A new antibiotic kills pathogens without detectable resistance. Nature 517: 455-459.

Martiny, A.C., Treseder, K., and Pusch, G. (2013) Phylogenetic conservatism of functional traits in microorganisms. ISME J 7: 830-838.

McGenity, T.J. (2016) An introduction to cultivation of hydrocarbon-cycling microbes. In Hydrocarbon and Lipid Microbiology Protocols: Isolation and Cultivation. T.J. McGenity, K.N. Timmis, B. Nogales (ed.) Springer, Berlin. doi:10.1007/8623_2015_177.

McGenity, T.J., Folwell, B.D., McKew, B.A., and Sanni G.O. (2012) Marine crude-oil biodegradation: a central role for interspecies interactions Aqu Biosys 8: 10.

McGenity, T.J., Crombie, A.T., Murrell, J.C. (2018) Microbial cycling of isoprene, the most abundantly produced biological volatile organic compound on Earth. ISME J 12: 931-941.

Molinari, G. (2009) Natural products in drug discovery: present status and perspectives. In C.A. Guzman and G.Z. Feuerstein (eds.) Pharmaceutical Biotechnology, Landes Bioscience. pp 13-27.

Mykytczuk, N.C., Foote, S.J., Omelon, C.R., Southam, G., Greer, C.W., and Whyte, L.G. (2013) Bacterial growth at $-15^{\circ} \mathrm{C}$; molecular insights from the permafrost bacterium Planococcus halocryophilus Or1. ISME J 7: 1211-1226.

Overmann, J., Abt, B., and Sikorski, J. (2017) Present and future of culturing bacteria. Annu Rev Microbiol 71: 711-730. 
Pelz, O., Tesar, M., Wittich, R.M., Moore, E.R.B., Timmis, K.N., and Abraham, W.R. (1999) Towards elucidation of microbial community metabolic pathways: unravelling the network of carbon sharing in a pollutant-degrading bacterial consortium by immunocapture and isotopic ratio mass spectrometry. Environ Microbiol 1: 167-174.

Phelan, V.V., Liu, W-T., Pogliano, K., and Dorrestein P.C. (2012) Microbial metabolic exchange-the chemotype-to-phenotype link. Nat Chem Biol 8: 26-35.

Pires D.P., Melo L., Vilas Boas D., Sillankorva S., and Azeredo J. (2017) Phage therapy as an alternative or complementary strategy to prevent and control biofilm-related infections. Curr Opin Microbiol 39: 48-56.

Puente-Sánchez, F., Arce-Rodríguez, A., Oggerin, M., García-Villadangos, M., Moreno-Paz, M., Blanco, Y., et al. (2018) Viable cyanobacteria in the deep continental subsurface. Proc Natl Acad Sci USA doi.org/10.1073/pnas.1808176115.

Pye, C.R., Bertin, M.J., Lokey, R.S., Gerwick, W.H., and Linington, R.G. (2017) Retrospective analysis of natural products provides insights for future discovery trends. Proc Natl Acad Sci USA 114: 56015606.

Richter, L.V., Mansfeldt, C.B., Kuan, M.M., Cesare, A.E., Menefee, S.T., Richardson, R.E., et al. (2018) Altered microbiome leads to significant phenotypic and transcriptomic differences in a lipid accumulating chlorophyte. Environ Sci Technol 52: 6854-6863.

Rosenthal, A.Z., Qi, Y., Hormoz, S., Park, J., Li, S. H-J., and Elowitz, M. (2018) Metabolic Interactions between dynamic bacterial subpopulations. eLife 7: e33099.

Røy, H., Kallmeyer, J., Adhikari, R. R., Pockalny, R., Jørgensen, B. B., and D'Hondt, S. (2012). Aerobic microbial respiration in 86-million-year-old deep-sea red clay. Science 336: 922-925.

Schirmer, M., Smeekens, S. P., Vlamakis, H., Jaeger, M., Oosting, M., Franzosa, E. A., et al. (2016) Linking the human gut microbiome to inflammatory cytokine production capacity. Cell 167: 11251136.

Seymour, J.R., Amin, S.A., Raina, J.B., and Stocker, R. (2017) Zooming in on the phycosphere: the ecological interface for phytoplankton-bacteria relationships. Nat Microbiol 2: 17065.

Shi, Y., Pan, C., Wang, K., Chen, X., Wu, X., Chen, C.-T., and Wu, B. (2017) Synthetic multispecies microbial communities reveals shifts in secondary metabolism and facilitates cryptic natural product discovery. Environ Microbiol 19: 3606-3618.

Singer, E., Wagner, M., and Woyke, T. (2017) Capturing the genetic makeup of the active microbiome in situ. ISME J 11: 1949-1963.

Smith, M.B., Rocha, A.M., Smillie, C.S., Oleson, S.W., Paradis, C., Wu, L., et al. (2015) Natural bacterial communities serve as quantitative geochemical biosensors. MBio 6: 1-13.

Sommer, F., and Bäckhed, F. (2013) The gut microbiota - masters of host development and physiology. Nat Rev Microbiol 11: 227-238. 
Steinle, L., Knittel, K., Felber, N., Casalino, C., de Lange, G., Tessarolo, C. et al. (2018) Life on the edge - active microbial communities in the $\mathrm{Kryos}_{\mathrm{MgCl}}$-brine basin at very low water activity ISME J 12: 1414-1426.

Stevenson, A., Cray, J.A., Williams, J.P., Santos, R., Sahay, R., Neuenkirchen, N. et al. (2015) Is there a common water-activity limit for the three domains of life? ISME J 9: 1333-1351.

Stevenson, A., Hamill, P.G., O’Kane, C.J., Kminek, G., Rummel, J.D., Voytek, M.A., Dijksterhuis, J., and Hallsworth, J.E. (2016) Aspergillus penicillioides differentiation and cell division at 0.585 water activity. Environ Microbiol 19: 687-697.

Symmons, M.F., Marshall, R.L., and Bavro, V.N. (2015) Architecture and roles of periplasmic adaptor proteins in tripartite efflux assemblies. Front Microbio/ 6: 513.

Tenaillon, O., Barrick, J.E., Ribeck, N., Deatherage, D.E., Blanchard, J.L., Dasgupta, A., et al. (2016) Tempo and mode of genome evolution in a 50,000-generation experiment. Nature 536: 165-170

Timmis, K.N., de Vos, W., Ramos, J.L., Vlaeminck, S.E., Prieto, A., Danchin, A., et al. (2017) The contribution of microbial biotechnology to sustainable development goals. Microb Biotechnol 10: 984-987.

Tracanna, V., de Jong, A., Medema, M.H., and Kuipers, O.P. (2017) Mining prokaryotes for antimicrobial compounds: From diversity to function. FEMS Microbiol Rev 41: 417-429.

Trindade, M., van Zyl, L. J., Navarro-Fernández, J., and Abd Elrazak, A. (2015) Targeted metagenomics as a tool to tap into marine natural product diversity for the discovery and production of drug candidates. Front Microbiol 6: 890.

Vanwonterghem, I., Evans, P.N., Parks, D.H., Jensen, P.D., Woodcroft, B.J., Hugenholtz, P., and Tyson, G.W. (2016) Methylotrophic methanogenesis discovered in the archaeal phylum

Verstraetearchaeota. Nat Microbiol 1: 16170.

Wang, M., Carver, J.J., Phelan, V.V., Sanchez, L.M., Garg, N., Peng, Y. et al. (2016) Sharing and community curation of mass spectrometry data with global natural products social molecular networking. Nat Biotechnol 34: 828-837.

Wang, Z., Fan G., Hryc, C.F., Blaza, J.N., Serysheva, I.I., Schmid, M.F., Chiu, W., Luisi, B.F., and Du, D. (2017) An allosteric transport mechanism for the AcrAB-TolC multidrug efflux pump. elife 6: e24905.

Webster, N.S., Wagner, M., and Negri, A.P. (2018) Microbial conservation in the Anthropocene. Environ Microbiol 20: 1925-1928.

Widder, S., Allen, R.J., Pfeiffer, T., Curtis, T.P., Wiuf, C., Sloan, W.T. et al. (2016) Challenges in microbial ecology: building predictive understanding of community function and dynamics. ISME J 10: $2557-2568$.

Youngquist, C.P., Mitchell, S.M., and Cogger, C.G. (2016) Fate of antibiotics and antibiotic resistance during digestion and composting: a review. J Environ Qual 45: 537-545. 
Ziegenbalg, S.B., Birgel, D., Hoffmann-Sell, L., Pierre, C., Roche, J.M., and Peckmann, J. (2012) Anaerobic oxidation of methane in hypersaline Messinian environments revealed by ${ }^{13} \mathrm{C}$-depleted molecular fossils. Chem Geol 292-293: 140-148.

Zhou, Z., Pan, J., Wang, F., Gu, J.-D., and Li, M. (2018) Bathyarchaeota: globally distributed metabolic generalists in anoxic environments. FEMS Microbiol Rev 42: 639-655. 